\title{
Dialysate cell-free mitochondrial DNA fragments as a marker of intraperitoneal inflammation and peritoneal solute transport rate in peritoneal dialysis
}

\author{
Xishao Xie, Junni Wang, Shilong Xiang, Zhimin Chen, Xiaohui Zhang and Jianghua Chen ${ }^{*}$ (1)
}

\begin{abstract}
Background: Mitochondrial DNA (mtDNA) released into extracellular subsequent to cell injury and death can promote inflammation in patients and animal models. However, the effects of peritoneal dialysate cell-free mtDNA on intraperitoneal inflammation and peritoneal solute transport rate (PSTR) in peritoneal dialysis (PD) patients remain unclear.

Methods: We select the incident patients who began PD therapy between January 1, 2009, and December 30, 2010. Peritoneal dialysate was collected at the time of peritoneal equilibration test. The cell-free mtDNA, IL-6, LL-17A, TNF-a and IFN- $\gamma$ were measured. All patients were followed till December 2017. The results were compared with PSTR and patient survival.

Results: One hundred and eighty-nine patients were included in the study. The average age was $47.1 \pm 13.5$ years, $55.6 \%$ of the patients were males. The average PSTR was $0.66 \pm 0.12$, the median dialysate mtDNA levels were 4325 copies/ul. The median concentrations of IL-6, IL-17A, TNF- $a$ and IFN- $\gamma$ were 25.9, 10.8, 25.8 and $17.9 \mathrm{pg} / \mathrm{ml}$, respectively. We found that dialysate mtDNA was significantly correlated with PSTR $(r=0.461, P<0.001), \mathrm{LL}-6(r=0.568, P<0.001)$, TNF-a $(r=0.454$, $P<0.001)$ and IFN- $\gamma(r=0.203, P=0.005)$. After adjustment for multiple covariates, dialysate mtDNA levels were independently correlated with IL-6 and PSTR. Dialysate mtDNA levels were not associated with patient survival.

Conclusions: We found that dialysate mtDNA levels correlated with the degree of intraperitoneal inflammatory status in PD patients. Peritoneal effluent mtDNA was an independent determinant of PSTR but did not affect patient survival.
\end{abstract}

Keywords: Mitochondrial DNA, Inflammation, Peritoneal solute transport rate, Peritoneal dialysis

\section{Background}

The structural and functional integrity of peritoneal membrane was the essential for peritoneal dialysis (PD). Peritoneal membrane function varies widely among individuals, and incident PD patients with a high peritoneal solute transport rate (PSTR) have been linked to increased mortality and technique failure [1-3]. The associations of local, chronic peritoneal inflammation with PSTR have been reported in prior studies [4-6], and the multicenter GLOBAL study has demonstrated that the intraperitoneal inflammation (dialysate IL-6) is the most

\footnotetext{
*Correspondence: zjukidney@zju.edu.cn

The Kidney Disease Center, The First Affiliated Hospital, College of Medicine, Zhejiang University, 79 Qingchun Rd, Hangzhou, Zhejiang 310003, People's Republic of China
}

(c) The Author(s). 2019 Open Access This article is distributed under the terms of the Creative Commons Attribution 4.0 International License (http://creativecommons.org/licenses/by/4.0/), which permits unrestricted use, distribution, and reproduction in any medium, provided you give appropriate credit to the original author(s) and the source, provide a link to the Creative Commons license, and indicate if changes were made. The Creative Commons Public Domain Dedication waiver (http://creativecommons.org/publicdomain/zero/1.0/) applies to the data made available in this article, unless otherwise stated.

reliable predictor of PSTR [7]. However, the cause of chronic intarperitoneal inflammation is not completed understood.

Besides of exogenous pathogen-associated molecular patterns (PAMPs), such as lipopolysaccharides (LPS), peptidoglycan and bacterial DNA, many studies have noted that various endogenous damage-associated molecular patterns (DAMPs) could activate the immune system in a non-infectious state $[8,9]$. Mitochondria was evolved from saprophytic bacteria to endosymbionts to organelles, and Mitochondrial DNA (mtDNA) shows similarities to bacterial DNA [10]. mtDNA released into the extracellular space subsequent to cell injury and death acts as DAMPs could induce inflammatory response through Toll-like receptor 9 (TLR9) pathway [11, 12]. 
Increased plasma mtDNA levels have been found in patients with trauma, sepsis and some autoimmune diseases, and were associated with the inflammation status and survival [13-16]. In PD patients, the PD catheters, long-term exposures to PD solutions and repeated peritonitis episodes could induce cell injury and death, which would lead to an abundant release of mtDNA into local intraperitoneal cavity. The purpose of the present study was to explore the relationships between mtDNA in peritoneal dialysate and intraperitoneal inflammation, PSTR and survival in PD patients.

\section{Methods}

\section{Study population}

All ESRD patients who began PD therapy at the First Affiliated Hospital of Zhejiang University in China between January 2009 and December 2010 were considered eligible for this study. Exclusion criteria were as follows: an age below 18 or above 80 years, a follow-up of less than 6 months, without peritoneal permeability test (PET) within 6 months after the initiation of PD therapy, peritonitis in the previous 1 month before PET. This study was approved by the Clinical Research Ethics Committee of the First Affiliated Hospital of Zhejiang University and performed in compliance with the Declaration of Helsinki. All participants provided informed consent before enrollment.

Baseline clinical data including age, gender cause of ESRD, body mass index (BMI), comorbid conditions, were recorded. The Charlson comorbidity index (CCI) was used to calculate a comorbidity score [17]. The collected biochemical data at the time of PET included hemoglobin, serum albumin and high sensitive $\mathrm{C}$-reactive protein. All the biochemical parameters were assessed in the center laboratory of our hospital. PD-related data including dialysis regimen and dose were recorded. Standard PET was performed by the method of Twardowski [18], and peritoneal solute transport rate (PSTR: dialysate-to-plasma creatinine ratio) and ultrafiltration capacity at $4 \mathrm{~h}$ with $2.5 \%$ glucose were calculated. The glucose exposure was measured as total grams of glucose within the daily dialysate. Residual renal function was calculated as the mean of the urea and creatinine clearance. Total Kt/Vurea and peritoneal Kt/ Vurea were calculated based on 24-h urine and dialysate collection using PD Adequest software (Baxter Healthcare).

\section{Dialysate mitochondrial DNA and cytokines level}

Dialysate sample was collected from a 4-h PET. The sample was centrifuged for at $1500 \mathrm{~g}$ at $4{ }^{\circ} \mathrm{C}$ for $10 \mathrm{~min}$, and the supernatant was saved and kept frozen at $-80^{\circ} \mathrm{C}$ until analysis. DNA was extracted from $200 \mathrm{ul}$ of dialysate supernatant using QIAamp DNA Mini Kit and Blood Mini Kit (Qiagen). The concentration of mtDNA was measured with mitochondrial cytochrome B (Cyto B, forwad 5' -ATGACCCCAATACGCAAAAT-3', reverse 5'-CGAA
GTTTCATCATGCGGAG-3') genes by real-time quantitative polymerase chain reaction (qPCR) assay (Applied Biosystems). The qPCR reacton mixture consisted of $10 \mathrm{ul} 2 \times$ SYBR Green Master Mix (Applied Biosystems), 0.5 ul forward primer $(5 \mathrm{uM}), 0.5 \mathrm{ul}$ reverse primer $(5 \mathrm{uM})$ of DNA and 4 ul nuclease-free water. qPCR was carried out as follows: a first denaturation step at $95^{\circ} \mathrm{C}$, and followed by 40 cycles at $95^{\circ} \mathrm{C}$ for $30 \mathrm{~s}, 53^{\circ} \mathrm{C}$ for $30 \mathrm{~s}$ and $72^{\circ} \mathrm{C}$ for 30s. The absolute values of mtDNA were determined by calculation from a stand curve using a cloned plasmid DNA (Additional file 1: Figure S1), as has been described previously $[19,20]$. The mtDNA levels in dialysate were expressed in copies/ul.

Dialysate supernatant IL-6, IL-17A, TNF- $\alpha$ and IFN- $\gamma$ levels were assessed by ELISA (R\&D System) following the protocol recommended by the manufacturer.

\section{Clinical follow-up}

The primary outcome measure was patient survival. Death and transfer to hemodialysis were regarded as composite endpoint events. Kidney transplantation was regarded as the censored event. All patients were followed till December 31, 2017.

\section{Statistical analysis}

Continuous variables are presented as means \pm SD or the medians with the interquartile ranges, and categorical variables are presented as frequencies with percentages. Differences between groups were compared with independent $\mathrm{t}$ test, Kruskal-Wallis test, chi-square tests, or one-way ANOVA test as appropriate.

Dialysate mtDNA and cytokines were $\log _{10}$ transformed and the correlations between mtDNA and cytokines and Kt/Vurea were assessed by Pearson's correlation analysis. General linear regression model was used to identify the predictors of IL- 6 and PSTR. Covariates with $P$-value $<0.1$ in univariate models were selected for multivariate regression models.

Survival was analyzed using the Kaplan-Meier method, and the groups were compared using a log-rank test. The patients were divided into the following 3 groups based on the mtDNA level tertiles: tertile $1 \quad(<2630$ copies/ul), tertile $2(2630 \sim 6300$ copies/ul) and tertile 3 (>6300 copies/ul). The Cox proportional hazards regression model was used to identify independent predictors of patient survival after adjusting for potential confounders. All statistical analyses were performed using SPSS version 22.0 (SPSS Inc.). A value of $P<0.05$ was considered statistically significant.

\section{Results}

Patient characteristics

A total of 189 patients were included in the final analysis (Fig. 1). The baseline clinical and biochemical data are 


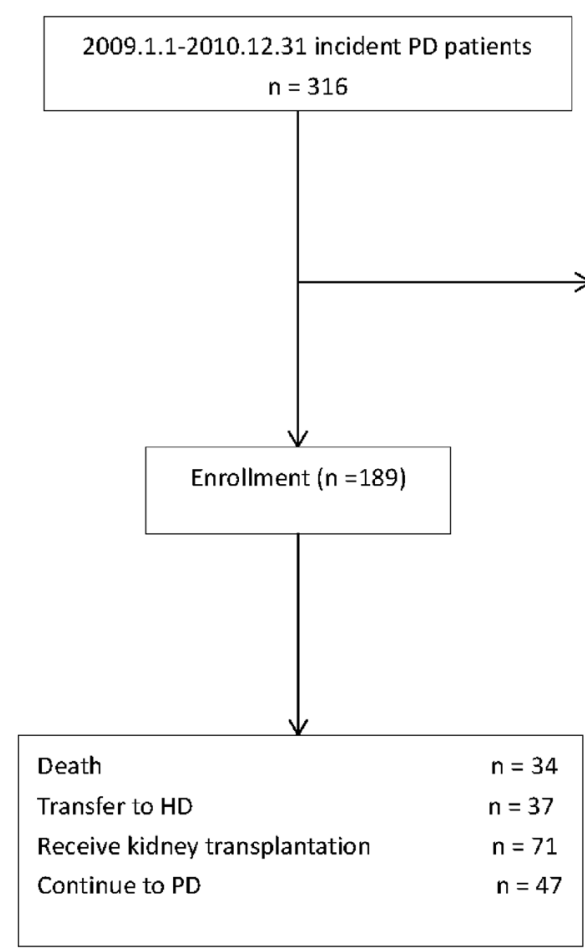

Excluded

Age $<18$ or $>80$ years $(n=9)$

Recovery of kidney function ( $n=5$ )

PD duration < 6 mo $(n=24)$

without PET data duration the first $6 \mathrm{mo}(n=70)$

Overt peritonitis with in 1 mo before PET $(n=4)$

With unavailable dialysate sample $(n=13)$

With unavailable follow-up data $(n=2)$

Fig. 1 Flow chart of the participants in the study cohort

summarized in Table 1 . The mean age of the cohort was $47.1 \pm 13.5$ years, $55.6 \%$ of the patients were male. The median time of PET was 2.7 months after initiation of $\mathrm{PD}$, and the mean PSTR was $0.66 \pm 0.12$. The median level of dialysate mtDNA was 4325 copies/ul. For incident patient, the timing of the initial PET had no significant effect on the level of mtDNA ( $<3$ mo vs. $>3$ mo, $P=0.194$, Additional file 1: Figure $\mathrm{S} 2$ ). The median levels of dialysate IL-6, IL-17A, TNF- $\alpha$ and IFN- $\gamma$ was $25.9 \mathrm{pg} / \mathrm{mL}, 10.8 \mathrm{pg} /$ $\mathrm{mL}, 25.8 \mathrm{pg} / \mathrm{mL}$ and $17.9 \mathrm{pg} / \mathrm{mL}$, respectively (Table 2).

\section{Correlation between mtDNA, cytokines and PSTR}

Results of correlation analysis between mtDNA and cytokines are shown in Table 3. Dialysate mtDNA levels were significantly correlated with dialysate IL-6 $(r=0.568, P<0.001)$, TNF- $\alpha(r=0.454, P<0.001)$ and IFN- $\gamma(r=0.203, P=0.005)$ concentrations. No relationship between dialysate mtDNA and IL-17A was observed $(r=0.027, P=0.710)$. Dialysate mtDNA level had significant correlation with PSTR $(r=0.461, P<$ 0.001 , Fig. 2). PSTR also significantly correlated with IL-6, TNF- $\alpha$ and IFN- $\gamma$ (Additional file 1: Figure S3).

\section{Factors associated with IL- 6 and PSTR}

Results of the multivariable general linear regression models showing the predictors of IL- 6 and PSTR are summarized in Tables 4 and 5 (Results of univariate analysis was shown in Additional file 1: Table S1 and S2).
Dialysate mtDNA was significantly associated with IL-6 after adjusting for other confounders including age, sex, serum albumin, IL-17A, TNF- $\alpha$ and IFN- $\gamma$, all of which had significant associations. mtDNA, IL-6, sex, and the use of $2.5 \%$ glucose solution was independently associated with PSTR.

\section{Associations of mtDNA levels with Kt/Vurea and patient survival}

Patients contributed a total of 9676.8 months of follow-up. During the study period, 34 (18.0\%) patients died, 37 (19.6\%) were transferred to HD, and $71(37.6 \%)$ patients underwent kidney transplantation. No significant relationship between baseline dialysate mtDNA and peritoneal Kt/ Vurea was observed $(r=-0.26, P=0.719)$, and there was no significant difference in peritoneal $\mathrm{Kt} / \mathrm{Vurea}$ and total $\mathrm{Kt} / \mathrm{Vurea}$ was observed between the three groups during during the study period. Similar results were also observed between dialysate mtDNA and total Kt/Vurea (Additional file 1: Figure S4). At 60 months, the overall patient survival was $61.2,66.3$ and $69.3 \%$ for dialysate mtDNA level tertile 1 , tertile 2 and tertile 3 , respectively. There was no significant difference in patient survival between the three $\operatorname{groups}(P=0.462$, Fig. 3$)$. According to the multivariable Cox proportional hazards model analysis, age, Charlson comorbidity score, $24 \mathrm{~h}$ urine volume, serum albumin and hemoglobin were significantly associated 
Table 1 Study population characteristics

\begin{tabular}{|c|c|}
\hline & Total (189) \\
\hline Sex (male: female) & 105:84 \\
\hline Age (years) & $47.1 \pm 13.5$ \\
\hline \multicolumn{2}{|l|}{ Primary renal disease } \\
\hline Chronic glomerulonephritis (\%) & $133(70.4)$ \\
\hline Diabetic nephropathy (\%) & $10(5.3)$ \\
\hline Hypertensive nephrosclerosis (\%) & $21(11.1)$ \\
\hline Obstructive nephropathy (\%) & $8(4.2)$ \\
\hline Polycystic kidneys (\%) & $4(2.1)$ \\
\hline Other/unknown (\%) & $13(6.9)$ \\
\hline $\mathrm{BMI}\left(\mathrm{kg} / \mathrm{m}^{2}\right)$ & $21.0 \pm 3.0$ \\
\hline Diabetes (\%) & $23(12.2)$ \\
\hline $\mathrm{CCl}$ & $3.0 \pm 1.3$ \\
\hline Hemoglobin (g/dL) & $8.2 \pm 1.6$ \\
\hline Serum albumin (g/L) & $38.1 \pm 5.4$ \\
\hline $\mathrm{hs}-\mathrm{CRP}(\mathrm{mg} / \mathrm{dL})$ & $2.4(1.1-4.1)$ \\
\hline Residual GFR (ml/min) & $7.3 \pm 2.5$ \\
\hline urine volume (ml/24 h) & $900(500-1300)$ \\
\hline Ultrafiltration volume (ml/24) & $250(100-500)$ \\
\hline Total dialysate volume (L/24 h) & $5.5 \pm 1.4$ \\
\hline Dialysate glucose exposure (g/24 h) & $90(60-110)$ \\
\hline $2.5 \%$ glucose solution use (\%) & $97(51.3)$ \\
\hline \multicolumn{2}{|l|}{ Peritoneal transport status } \\
\hline High (\%) & $18(9.5)$ \\
\hline High average (\%) & $57(30.2)$ \\
\hline Low average (\%) & $57(30.2)$ \\
\hline Low (\%) & $20(10.6)$ \\
\hline $\operatorname{PSTR}(4 \mathrm{~h})$ & $0.66 \pm 0.12$ \\
\hline Time of PET (months) & $2.7(1.9-4.7)$ \\
\hline Peritoneal Kt/Nurea & $1.11 \pm 0.45$ \\
\hline Total Kt/Vurea & $2.15 \pm 0.56$ \\
\hline Follow-up (months) & $41.9(22.4-63.5)$ \\
\hline
\end{tabular}

Abbreviations: BMI, body mass index; $\mathrm{CCl}$, Charlson comorbidity index; hs-CRP, high sensitivity C-reactive protein; Residual GFR, residual glomerular filtration rate; PSTR, Peritoneal solute transport rate; PET, Peritoneal equilibration test

Table 2 Dialysate mtDNA and cytokine concentrations

\begin{tabular}{ll}
\hline & Total $(n=189)$ \\
\hline mtDNA (copies/uL) & $4325(1967-8766)$ \\
IL-6 $(\mathrm{pg} / \mathrm{mL})$ & $25.9(18.8-32.2)$ \\
IL-17A $(\mathrm{pg} / \mathrm{mL})$ & $10.8(9.9-11.8)$ \\
TNF- $a(\mathrm{pg} / \mathrm{mL})$ & $25.8(18.9-28.4)$ \\
IFN- $\gamma(\mathrm{pg} / \mathrm{mL})$ & $17.9(15.2-20.5)$ \\
\hline
\end{tabular}

Abbreviations: mtDNA, Mitochondrial DNA
Table 3 Correlation analysis between mtDNA and cytokines

\begin{tabular}{llllll}
\hline & & mtDNA & IL-6 & IL-17 & TNF- \\
\hline IL-6 & $r$ & 0.568 & & & \\
& $p$ & $<0.001$ & & & \\
IL-17A & $r$ & -0.004 & 0.185 & & \\
& $p$ & 0.959 & 0.011 & & \\
TNF-a & $r$ & 0.454 & 0.580 & 0.065 & \\
& $p$ & $<0.001$ & $<0.001$ & 0.372 & \\
IFN- $\gamma$ & $r$ & 0.203 & 0.390 & 0.279 & 0.220 \\
& $p$ & 0.005 & $<0.001$ & $<0.001$ & 0.002 \\
\hline
\end{tabular}

mtDNA and cytokine coefficients are per $\log _{10}$ changes in concentrations

with patient survival, whereas dialysate mtDNA had no independent effect (Additional file 1: Table S3).

\section{Discussion}

In the present study, we found that dialysate mtDNA level was significantly associated with the degree of local intraperitoneal IL-6 level, and was a predictor of PSTR. No significantly correlations were founded between dialysate mtDNA and survival in PD patients.

Increasing evidence from studies supports that mtDNA released from injured cells into extracellular space acts as a DAMP and plays an important role in inflammatory responses [11, 21-23]. mtDNA contains unmethylated CpG DNA motifs similar to bacterial DNA, which could bind to TLR9 and activate the downstream inflammatory cascades. Zhang et al. showed that injection of mtDNA could induce proinflammatory cytokines accumulation and acute lung injury with infiltration of polymorphonuclear neutrophils in mice [24], suggesting the direct roles of mtDNA on inflammation and tissue injuries. Tsuji et al. also demonstrated that mtDNA could activate TLR9 and contributes to cytokines production and acute kidney injury during polymicrobial sepsis [25]. Clinical studies have reported that cell-free mtDNA levels in plasma were elevated in several diseases, such as trauma [13, 26], bacterial meningitis [27], sepsis [28, 29], myocardial infarction [30, 31], and maintenance dialysis [32, 33], and were associated with systemic inflammation and mortality.

Although the chronic local intraperitoneal inflammation in PD patients has been demonstrated in prior studies $[5,6,34]$, the source and mechanism of local inflammation has not been completely understood. In PD patients, mtDNA could be released to peritoneal cavity in response to repeated exposures to conventional PD solutions and peritonitis episodes. We hypothesize that mtDNA was a pro-inflammatory factor in peritoneal dialysis and we found that dialysate mtDNA was positively correlated with IL-6, TNF- $\alpha$ and IFN- $\gamma$, and dialysate mtDNA was a strong predictor of the degree of intraperitoneal inflammation after adjusting for other confounders. To our best knowledge, this is the first study to describe the role of 


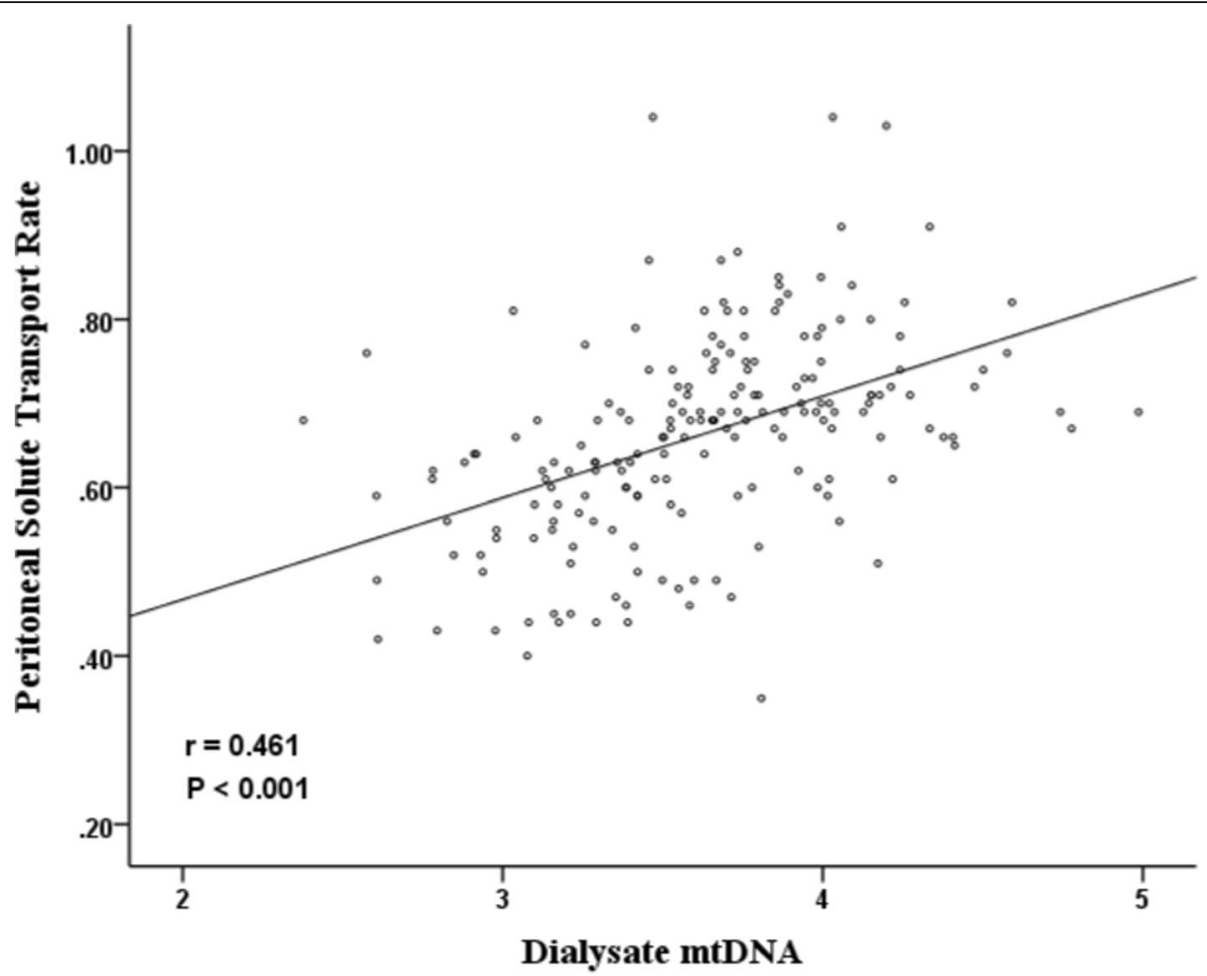

Fig. 2 Scatterplot of PSTR with dialysate mtDNA. mtDNA coefficient was per $\log _{10}$ changes in concentrations. A positive correlation between dialysate mtDNA and PSTR was observed

mtDNA in intraperitoneal inflammation in PD patients. Another important observation from our study was the significant association of dialysate mtDNA levels and PSTR. Studies have reported that local subclinical inflammation contributes to progressive peritoneal injury and changes in PSTR [35-37]. The GLOBAL study demonstrated that the local production of IL-6 was the strongest known factor correlated with variability in PSTR in incident PD patients [7], and the balANZ study showed that the increased dialysate IL-6 concentration were able to predict the change in PSTR with longer PD duration [5]. In addition to dialysate IL-6, our study also found that dialysate mtDNA levels were positively associated with

Table 4 Predictors of IL-6

\begin{tabular}{lll}
\hline Variable & Coefficient $(95 \% \mathrm{Cl})$ & $P$ Value \\
\hline Age (per 10 years) & $0.017(0.005$ to 0.029$)$ & 0.004 \\
Sex (Female) & $-0.032(-0.064$ to 0$)$ & 0.049 \\
BMI & $-0.003(-0.008$ to 0.002$)$ & 0.265 \\
Serum albumin (per 1 g/dl) & $-0.034(-0.064$ to -0.005$)$ & 0.021 \\
mtDNA & $0.118(0.079$ to 0.157$)$ & $<0.001$ \\
IL-17A & $0.276(0.030$ to 0.521$)$ & 0.028 \\
TNF- $a$ & $0.429(0.305$ to 0.554$)$ & $<0.001$ \\
IFN- $\gamma$ & $0.318(0.158$ to 0.478$)$ & $<0.001$ \\
\hline Abbris &
\end{tabular}

Abbreviations: BMI, body mass index; mtDNA and cytokine coefficients are per $\log _{10}$ changes in concentrations
PSTR independent of IL-6, the dialysate mtDNA levels in patients with high or high average PSTR were significantly higher than patients with low or low average PSTR $(P<$ 0.001). Recent studies showed that extracellular mtDNA could activate endothelial cells, promote adhesion of neutrophils to the endothelium and subsequently increase endothelial permeability [38]. These may partly explain the direct role of dialysate mtDNA on PSTR in PD patient, but the underlying mechanism and pathway needed to be further studied.

The GLOBAL study showed that the systemic inflammation (IL- 6 and TNF- $\alpha$ ) was the independent predictor of survival, whereas intraperitoneal inflammation and

Table 5 Predictors of PSTR

\begin{tabular}{lll}
\hline Variable & Coefficient $(95 \% \mathrm{Cl})$ & $P$ Value \\
\hline Sex (Female) & $-0.295(-0.575$ to -0.015$)$ & 0.039 \\
2.5\% glucose solution use & $0.761(0.257$ to 1.264$)$ & 0.003 \\
$\begin{array}{l}\text { Dialysate glucose exposure } \\
\text { (per 10 g) }\end{array}$ & $-0.118(-0.289$ to 0.053$)$ & 0.175 \\
Dialysate volume (per 1 L) & $0.296(-0.025$ to 0.617$)$ & 0.071 \\
mtDNA & $0.703(0.344$ to 1.062$)$ & $<0.001$ \\
IL-6 & $2.065(0.896$ to 3.234$)$ & 0.001 \\
TNF-a & $-0.108(-1.285$ to 1.070$)$ & 0.858 \\
IFN- $y$ & $1.377(-0.007$ to 2.762$)$ & 0.051 \\
\hline
\end{tabular}

mtDNA and cytokine coefficients are per $\log _{10}$ changes in concentrations 


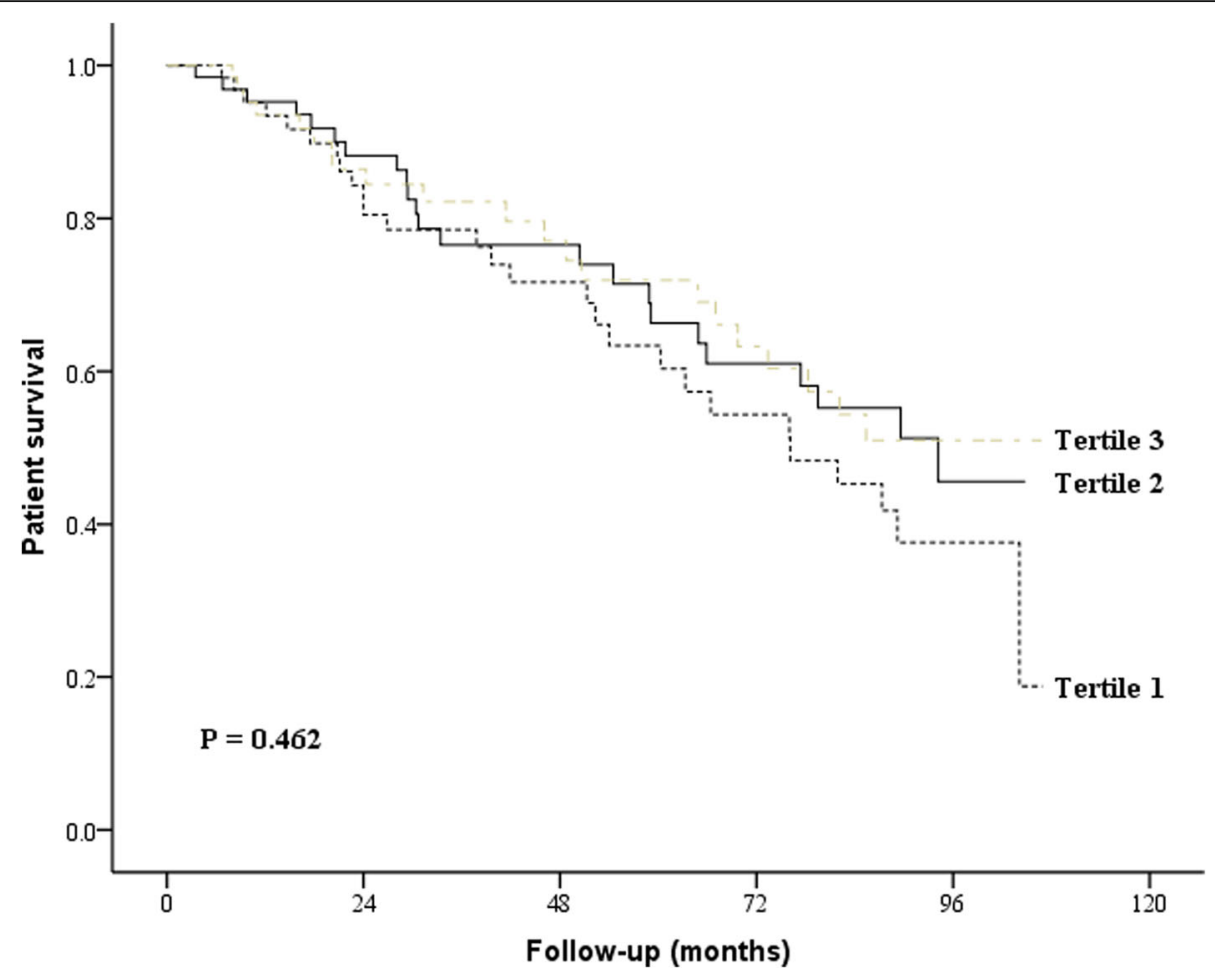

Fig. 3 Kaplan-Meier survival curves for the patients with different mtDNA levels (log-rank test, $P=0.462$ ). Death and transfer to hemodialysis were regarded as composite endpoint events

PSTR had no effect [7]. Our results were consistent with the GLOBAL study, in addition to dialysate cytokines levels and PSTR, no correlation between dialysate mtDNA and $\mathrm{Kt} / \mathrm{Vurea}$ or patient survival were observed in our study. Szeto et al. recently reported that the plasma cell-free mtDNA was a strong predictor of cardiovascular events and need of hospitalization in PD patients [32]. We haven't examined the plasma mtDNA levels, and more studies were needed to identify the relationships between plasma mtDNA levels and patient survival.

This study has several limitations. Firstly, it was a retrospective study based on the assay of archive dialysate samples from a single center, therefore, our findings only reveal associations and not causation due to the observational nature of the study. Secondly, Long-term storage of dialysate samples may inevitably lead to different degree of changes in mtDNA and cytokines levels, which may result in some bias. Thirdly, we have not examined the changes of dialysate mtDNA level with time, the influence of dynamic changes of dialysate mtDNA level during the observation period on intraperitoneal inflammatory status and PSTR remain unclear.

\section{Conclusion}

In conclusion, we showed that dialysate cell-free mtDNA level was significantly associated with the degree of local intraperitoneal IL-6 level during the first PET, and was a strong predictor of PSTR in PD patients, but not associated with survival. Further studies are needed to identify the underling mechanisms and investigate whether mtDNA can serve as a potential new therapeutic target for reducing the intraperitoneal inflammation and improving the peritoneal membrane function.

\section{Additional file}

Additional file 1: Figure S1. Standard curve and dissociation curve from cloned plasmid DNA. Figure S2. Dialysate cell-free mtDNA levels of PD patients grouped by the time of the initial PET $(<3$ mo vs. $>3 \mathrm{mo})$. Figure S3. Scatterplot of PSTR with dialysate cytokines. Cytokines coefficient was per $\log _{10}$ changes in concentrations. Figure S4. Changes of peritoneal $\mathrm{Kt} /$ Nurea and total Kt/Nurea during the follow up. Table S1. Predictors of IL6 (univariate analysis). Table S2. Predictors of PSTR (univariate analysis). Table S3. Risk factors of mortality (multivariable Cox regression model). (DOCX $377 \mathrm{~kb})$

\section{Acknowledgements}

We thank Duo Lv for her assistance in statistical analysis. This study was supported by the Natural Science Foundation of China (No. 91670621).

\section{Authors' contributions}

Research idea and study design: XX, XZ, and JC; data acquisition: XX, JW, SX, and ZC; data analysis/interpretation: $X X$ and JW; statistical analysis: $X X$ and JW; supervision or mentorship: $X Z$ and JC. All authors read and approved the final manuscript.

Competing interests

The authors declare that they have no competing interests. 


\section{Publisher's Note}

Springer Nature remains neutral with regard to jurisdictional claims in published maps and institutional affiliations.

Received: 3 December 2018 Accepted: 7 March 2019

Published online: 11 April 2019

\section{References}

1. Rumpsfeld M, McDonald SP, Johnson DW. Higher peritoneal transport status is associated with higher mortality and technique failure in the Australian and New Zealand peritoneal dialysis patient populations. J Am Soc Nephrol. 2006;17(1):271-8.

2. Brimble KS, Walker M, Margetts PJ, et al. Meta-analysis: peritoneal membrane transport, mortality, and technique failure in peritoneal dialysis. J Am Soc Nephrol. 2006;17:2591-8.

3. Davies SJ. Peritoneal solute transport and inflammation. Am J Kidney Dis. 2014;64:978-86.

4. Oh KH, Jung JY, Yoon MO, et al. Intra-peritoneal interleukin-6 system is a potent determinant of the baseline peritoneal solute transport in incident peritoneal dialysis patients. Nephrol Dial Transplant. 2010;25:1639-46.

5. Cho Y, Johnson DW, Vesey DA, et al. Dialysate interleukin-6 predicts increasing peritoneal solute transport rate in incident peritoneal dialysis patients. BMC Nephrol. 2014;15:8.

6. Pecoits-Filho R, Carvalho MJ, Stenvinkel $P$, et al. Systemic and intraperitoneal interleukin-6 system during the first year of peritoneal dialysis. Perit Dial Int. 2006;26:53-63.

7. Lambie M, Chess J, Donovan KL, et al. Independent effects of systemic and peritoneal inflammation on peritoneal dialysis survival. J Am Soc Nephrol. 2013:24:2071-80

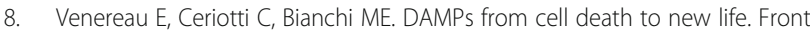
Immunol. 2015:6:422.

9. Patel S. Danger-associated molecular patterns (DAMPs): the derivatives and triggers of inflammation. Curr Allergy Asthma Rep. 2018;18(11):63.

10. Taanman JW. The mitochondrial genome: structure, transcription, translation and replication. Biochim Biophys Acta. 1999;1410:103-23.

11. Escames G, Lopez LC, Garcia JA, et al. Mitochondrial DNA and inflammatory diseases. Hum Genet. 2012:131:161-73.

12. Zhang Q, Itagaki K, Hauser CJ. Mitochondrial DNA is released by shock and activates neutrophils via p38 map kinase. Shock. 2010:34:55-9.

13. Simmons JD, Lee $Y L$, Mulekar $S$, et al. Elevated levels of plasma mitochondrial DNA DAMPs are linked to clinical outcome in severely injured human subjects. Ann Surg. 2013;258:591-8.

14. Gu X, Yao Y, Wu G, et al. The plasma mitochondrial DNA is an independent predictor for post-traumatic systemic inflammatory response syndrome. PLoS One. 2013;8:e72834.

15. Gentile LF, Moldawer LL. Damps, Pamps, and the origins of sirs in bacterial Sepsis. Shock. 2013;39:113-4.

16. Hajizadeh S, DeGroot J, TeKoppele JM, et al. Extracellular mitochondrial DNA and oxidatively damaged DNA in synovial fluid of patients with rheumatoid arthritis. Arthritis Res Ther. 2003:5:R234-40.

17. Charlson ME, Pompei $P$, Ales $K L$, et al. A new method of classifying prognostic comorbidity in longitudinal studies: development and validation. J Chronic Dis. 1987;40:373-83.

18. Twardowski ZJ, Nolph KD, Khanna R, et al. Peritoneal Equilibration Test. Periton Dialysis Int. 1987;7:138-47.

19. Chiu RW, Chan LY, Lam NY, et al. Quantitative analysis of circulating mitochondrial DNA in plasma. Clin Chem. 2003;49:719-26.

20. Walko TD 3rd, Bola RA, Hong JD, et al. Cerebrospinal fluid mitochondrial DNA: a novel DAMP in pediatric traumatic brain injury. Shock. 2014;41:499-503.

21. Nakahira K, Hisata S, Choi AM. The roles of mitochondrial damageassociated molecular patterns in diseases. Antioxid Redox Signal. 2015;23: 1329-50.

22. Arnoult D, Soares F, Tattoli I, et al. Mitochondria in innate immunity. EMBO Rep. 2011;12:901-10

23. West AP, Shadel GS. Mitochondrial DNA in innate immune responses and inflammatory pathology. Nat Rev Immunol. 2017;17(6):363-75.

24. Zhang $Q$, Raoof $M$, Chen $Y$, et al. Circulating mitochondrial DAMPs cause inflammatory responses to injury. Nature. 2010;464(7285):104-7.

25. Tsuji N, Tsuji T, Ohashi N, et al. Role of mitochondrial DNA in septic AKI via toll-like receptor 9. J Am Soc Nephrol. 2016;27:2009-20.
26. Yamanouchi S, Kudo D, Yamada M, et al. Plasma mitochondrial DNA levels in patients with trauma and severe sepsis: time course and the association with clinical status. J Crit Care. 2013;28:1027-31.

27. Lu CH, Chang WN, Tsai NW, et al. The value of serial plasma nuclear and mitochondrial DNA levels in adult community-acquired bacterial meningitis. QJM. 2010;103:169-75.

28. Puskarich MA, Shapiro NI, Trzeciak S, et al. Plasma levels of mitochondrial DNA in patients presenting to the emergency department with sepsis. Shock. 2012:38:337-40

29. Kung CT, Hsiao SY, Tsai TC, et al. Plasma nuclear and mitochondrial DNA levels as predictors of outcome in severe sepsis patients in the emergency room. J Transl Med. 2012;10:130.

30. Bliksoen M, Mariero LH, Ohm IK, et al. Increased circulating mitochondrial DNA after myocardial infarction. Int J Cardiol. 2012;158:132-4.

31. Arnalich F, Codoceo R, Lopez-Collazo E, et al. Circulating cell-free mitochondrial DNA: a better early prognostic marker in patients with outof-hospital cardiac arrest. Resuscitation. 2012;83(7):e162-3.

32. Szeto CC, Lai KB, Chow KM, et al. Plasma mitochondrial DNA level is a prognostic marker in peritoneal Dialysis patients. Kidney Blood Press Res. 2016;41:402-12.

33. Cao H, Ye H, Sun $Z$, et al. Circulatory mitochondrial DNA is a proinflammatory agent in maintenance hemodialysis patients. PLoS One. 2014;9:e113179.

34. Cho Y, Hawley CM, Johnson DW. Clinical causes of inflammation in peritoneal dialysis patients. Int J Nephrol. 2014;2014:909373.

35. Cho Y, Johnson DW. Peritoneal dialysis-related peritonitis: towards improving evidence, practices, and outcomes. Am J Kidney Dis. 2014;64:278-89.

36. Zhou L, Wen F, Chen $G$, et al. Cytokine profiles in peritoneal dialysis effluent predicts the peritoneal solute transport rate in continuous ambulatory peritoneal dialysis patients. Int J Clin Exp Med. 2015;8:20424-33.

37. Baroni G, Schuinski A, de Moraes TP, et al. Inflammation and the peritoneal membrane: causes and impact on structure and function during peritoneal dialysis. Mediat Inflamm. 2012:2012:912595.

38. Sun S, Sursal T, Adibnia Y, et al. Mitochondrial DAMPs increase endothelia permeability through neutrophil dependent and independent pathways. PLoS One. 2013;8(3):e59989.

\section{Ready to submit your research? Choose BMC and benefit from:}

- fast, convenient online submission

- thorough peer review by experienced researchers in your field

- rapid publication on acceptance

- support for research data, including large and complex data types

- gold Open Access which fosters wider collaboration and increased citations

- maximum visibility for your research: over $100 \mathrm{M}$ website views per year

At BMC, research is always in progress.

Learn more biomedcentral.com/submissions 